\section{References}

1. Pennathur A, Luketich JD, Abbas G, Chen M, Fernando HC, Gooding WE, et al. Radiofrequency ablation for the treatment of stage I non-small cell lung cancer in high-risk patients. J Thorac Cardiovasc Surg. 2007;134:857-64.

2. Lanuti M, Sharma A, Digurmarthy SR, Wright CD, Donahue DM, Wain JC, et al. Radiofrequency ablation for treatment of medically inoperable stage I non-small cell lung cancer. J Thorac Cardiovasc Surg. 2009;137:160-6.

3. Schneider T, Reuss D, Warth A, Schnabel PA, Von Deimling A, Herth FJF, et al. The efficacy of bipolar and multipolar radiofrequency ablation of lung neo- plasms: results of an ablate and resect study. Eur J Thorac Surg. 2011;39: 968-73.

4. Baumann P, Nyman J, Hoyer M, Wennberg B, Gagliardi G, Lax I, et al. Outcome in a prospective phase II trial of medically inoperable stage I non-small-cell lung cancer patients treated with stereotactic body radiotherapy. J Clin Oncol. 2009;27:3290-6.

5. Nagata Y, Takayama K, Matsuo Y, Norihisa Y, Mizowaki T, Sakamoto T, et al. Clinical outcomes of a phase I/II study of $48 \mathrm{~Gy}$ of stereotactic body radiation therapy in 4 fractions for primary lung cancer using a stereotactic body frame. Int $J$ Radiation Oncology Biol Phys. 2005;5:1427-31.

\title{
The role of methylene blue in serotonin syndrome following cardiac transplantation: A case report and review of the literature
}

\author{
Kendra J. Grubb, MD, ${ }^{a}$ Jamie L. W. Kennedy, MD, ${ }^{b}$ James D. Bergin, MD, ${ }^{b}$ Danja S. Groves, MD, PhD, ${ }^{c}$ and \\ John A. Kern, MD, ${ }^{a}$ Charlottesville, Va
}

Vasoplegic syndrome (VS) is a common complication of cardiopulmonary bypass, with an incidence reported between $5 \%$ and $25 \%$ for all cardiac operations. ${ }^{1,2}$ Associated with increased morbidity and mortality, ${ }^{2,3}$ VS is characterized by severe systemic arterial hypotension (mean arterial pressure, $<50 \mathrm{~mm} \mathrm{Hg}$ ) and low systemic vascular resistance $\left(<800\right.$ dyne $\left./ \mathrm{s} / \mathrm{cm}^{5}\right) .{ }^{1,3}$ The syndrome is particularly troubling in orthotopic heart transplant recipients as a result of the untoward effects of increased fluid and vasopressor requirements for resuscitation. Furthermore, VS is reported to occur in as many as $45 \%$ of patients with a ventricular assist device at the time of transplantation, making this a particularly high-risk surgical population. ${ }^{4}$

The blunting of nitric oxide release has been hypothesized to counter the endothelial dysfunction thought to cause vasoplegia. Methylene blue interacts with nitric oxide-mediated pathways via a number of mechanisms, including direct nitric oxide binding, inhibition of soluble guanylate cyclase, and inhibition of nitric oxide synthase..$^{5-7}$ Methylene blue has been shown to reverse refractory hypotension associated with vasoplegia. ${ }^{8-10}$ Furthermore, the benefits of methylene blue for the

\footnotetext{
From the Division of Thoracic, Cardiac, and Vascular Surgery, ${ }^{\mathrm{a}}$ the Division of Cardiovascular Medicine, ${ }^{\mathrm{b}}$ and the Department of Anesthesiology, ${ }^{\mathrm{c}}$ University of Virginia Health Systems, Charlottesville, Va.

Disclosures: Authors have nothing to disclose with regard to commercial support.

Received for publication April 23, 2012; revisions received June 22, 2012; accepted for publication July 25, 2012; available ahead of print Sept 17, 2012.

Address for reprints: Kendra J. Grubb, MD, University of Virginia Health System, Division of Thoracic, Cardiac, and Vascular Surgery, PO Box 800679, Charlottesville, VA 22908 (E-mail: kg8fg@virginia.edu).

J Thorac Cardiovasc Surg 2012;144:e113-6

$0022-5223 / \$ 36.00$

Copyright (C) 2012 by The American Association for Thoracic Surgery

http://dx.doi.org/10.1016/j.jtcvs.2012.07.030
}

treatment of VS have been well documented in cardiac surgery, and its usage associated with reduced mortality and morbidity. ${ }^{11,12}$

In an effort to circumvent the morbidity and mortality associated with VS, we have implemented successfully an intraoperative protocol that includes administration of methylene blue for VS resistant to vasopressor treatment. Until now, scant information has been reported about the untoward effects of methylene blue in the cardiac transplant patient population. Herein, we describe the first case of methylene blue-induced serotonin toxicity in a patient after cardiac transplant. A review of the current literature and U.S. Federal Drug Administration (FDA) warnings are included.

\section{CASE REPORT}

A 60-year-old male with history of nonischemic cardiomyopathy and end-stage heart failure underwent placement of a left ventricular assist device (LVAD) along with replacement of a mechanical aortic valve with a porcine prosthesis in March 2011. His LVAD course was complicated by multiple driveline infections with Pseudomonas, Serratia, and, most recently, Achromobacter. He was therefore listed for heart transplantation as a United Network for Organ Sharing status 1A. A donor organ became available and he was brought to the hospital for preoperative management of anticoagulation and preparation for transplant. Comorbidities included insulin-dependent diabetes mellitus, hypertension, obesity status-post gastric bypass surgery, peptic ulcer disease, chronic kidney disease, gout, and depression, for which he was taking escitalopram $20 \mathrm{mg}$ per ora daily as well as trazodone $100 \mathrm{mg}$ daily at bedtime.

He underwent a third-time redo sternotomy with femoral cannulation and initiation of cardiopulmonary bypass. After the aortic crossclamp was placed, he was noted to have 
episodes of hypotension during the extensive lysis of adhesions for LVAD removal. Intermittent boluses of phenylepherine were administered to maintain a sufficient mean arterial pressure. Subsequently, a methylene blue $1-\mathrm{mg} / \mathrm{kg}$ bolus followed by continuous infusion of $0.5 \mathrm{mg} / \mathrm{kg}$ per hour was administered. The hypotension resolved and a target mean arterial pressure $>50 \mathrm{~mm} \mathrm{Hg}$ on cardiopulmonary bypass was maintained. The remainder of the heart transplantation was unremarkable, with early recovery of normal ventricular function.

Postoperatively, the patient was noted to have delayed recovery from anesthesia. His physical examination was remarkable for ocular clonus, mydriasas, lateral nystagmus, and subsequent myoclonic jerks and shivering, as well as hypertonicity. He then developed a temperature of $40^{\circ} \mathrm{C}$ with concomitant hypoxia. His pressure requirement was moderate, with normal cardiac output by thermal dilution, but he exhibited a low mixed venous saturation consistent with a hypermetabolic state. Laboratory tests revealed a peak white cell count of $18.39 \times 10^{-9} \mathrm{k} / \mu \mathrm{L}$, an elevated creatinine level that peaked at $3.3 \mu \mathrm{mol} / \mathrm{L}$ from a preoperative baseline of $1.7 \mu \mathrm{mol} / \mathrm{L}$, and an increasing potassium level with a peak at $5.1 \mathrm{mmol} / \mathrm{L}$. Creatine phosphokinase peaked at $1406 \mathrm{U} / \mathrm{L}$. Computed tomography of the head revealed no acute pathology. Electroencephalography demonstrated slowing of electrocerebral function, consistent with encephalopathy resulting from toxic, metabolic, or pharmacologic changes. He was managed expectantly, and a neurology consult and toxicology consult were initiated.

A literature review was then undertaken querying for "methylene blue" and "nystagmus." Multiple reports and reviews were found describing the role of methylene blue in serotonin syndrome and serotonin toxicity in particular patients taking antidepressants. ${ }^{13,14}$ Based on his preoperative medication profile, clinical findings, negative head computed tomographic scan, and laboratory results, the diagnosis of serotonin syndrome was made. In that there is no treatment for serotonin syndrome, the patient was sedated with midazolam for 24 hours to allow clearance of methylene blue, and he remained intubated. The midazolam was weaned and no neurologic manifestations were noted 48 hours postoperatively. The patient was then extubated and recovered unremarkably. He was discharged to home on postoperative day 17.

\section{DISCUSSION}

\section{Serotonin Syndrome}

Serotonin syndrome is well described in the psychiatric and psychopharmacologic literature. The syndrome manifests at toxic levels of serotonergic agonism of central nervous system and peripheral serotonergic receptors. ${ }^{15-17}$ Most often this occurs in the setting of intentional overdose of antidepressants or from therapeutic

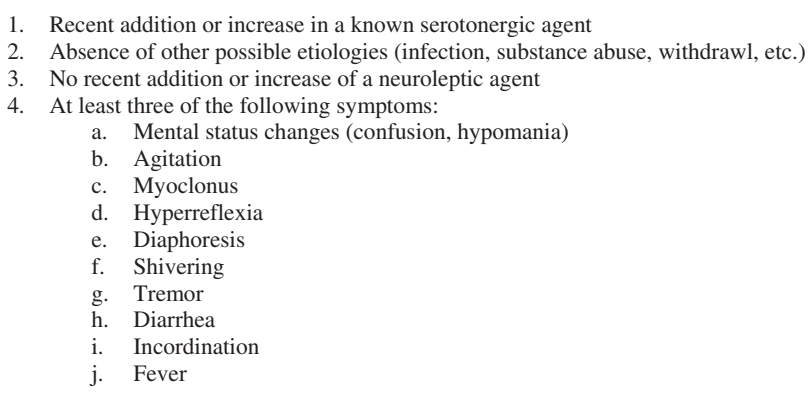

FIGURE 1. Sternbach's criteria. ${ }^{15}$

combination drug usage. The excess serotonin produces a spectrum of clinical findings, in a concentrationdependent toxicity, ranging from subtle mental status changes to a life-threatening adverse drug reaction. A triad of clinic features including (1) autonomic signs, (2) neuromuscular changes, and (3) altered mental status are salient features in the diagnosis of serotonin syndrome. ${ }^{16}$

In 1991, Sternbach ${ }^{15}$ derived diagnostic criteria for serotonin syndrome based on a review of case reports and case series. The criteria diagnose serotonin syndrome as the presence of $\geq 3$ specific clinical features in the setting of known usage of a serotonergic medication (Figure 1).

Because of the ambiguity of Sternbach's model, Dunkley and colleagues ${ }^{16}$ revised the criteria to diagnose serotonin toxicity accurately, based on review of 2222 patients presenting with overdose of serotonergic agents to the Hunter Area Toxicology Service in Australia from January 1987 to November 2002. The redefined criteria simplified the diagnosis for serotonin toxicity as well as increased the sensitivity $(84 \%)$ and specificity $(97 \%)$ of the model. To predict serotonin toxicity accurately, only the following clinical findings are needed: clonus (spontaneous, inducible, or ocular), agitation, diaphoresis, tremor, and/or hyperreflexia (Figure 2). Clonus is the most important clinical feature,

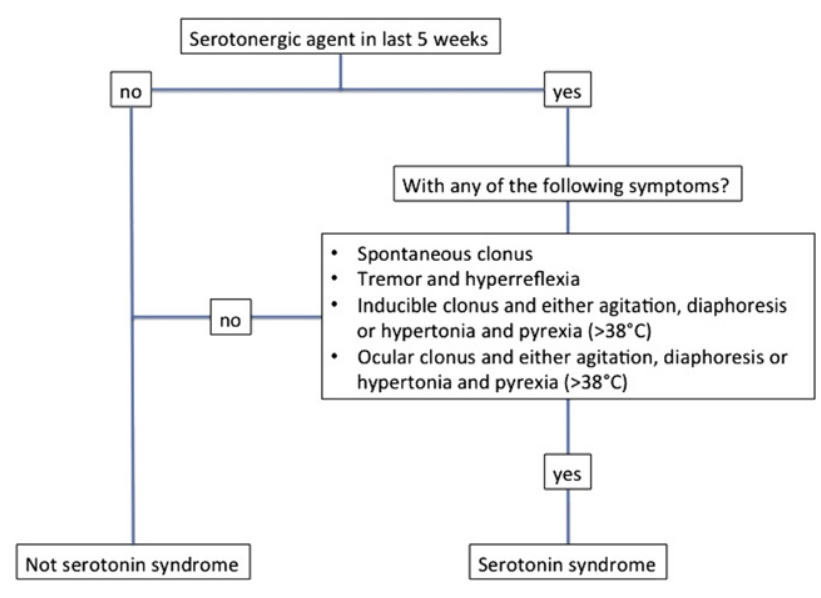

FIGURE 2. The Hunter serotonin toxicity criteria. ${ }^{16}$ 
TABLE 1. Drugs implicated in serotonin syndrome associated with the administration of methylene blue in the Food and Drug Administration Adverse Event Reporting System

\begin{tabular}{lll}
\hline \multicolumn{1}{c}{ Class } & Generic name & \multicolumn{1}{c}{ Brand names } \\
\hline $\begin{array}{l}\text { Selective serotonin reuptake } \\
\text { inhibitors }\end{array}$ & Paroxetine & Paxil, Paxil CR \\
& Fluvoxamine & Luvox, Luvox CR \\
& Fluoxetine & Prozac, Symbyax \\
& Sertraline & Zoloft \\
& Citalopram & Celexa \\
& Escitalopram & Lexapro \\
& Vilazodone* & Viibryd \\
& Venlafaxine & Effexor, Effexor XR \\
Serotonin norepinephrine & & \\
reuptake inhibitors & Desvenlafaxine & Pristiq \\
& Duloxetine & Cymbalta \\
& Clomipramine & Anafranil \\
Tricyclic antidepressants & Ailazodone was included because of the pharmacology of the drug, but no cases of \\
serotonin syndrome associated with Vilazodone have been reported.
\end{tabular}

as this finding is most strongly associated with serotonin toxicity.

\section{U.S. FDA Safety Communication}

During the past year, the U.S. FDA published drug safety communications that detail serious reactions when methylene blue is administered to patients taking psychiatric medications. On July 26, 2011, a drug safety communication was published recommending that methylene blue should generally not be given to patients taking serotonergic drugs. ${ }^{18}$ Furthermore, in nonemergency situations when methylene blue is contemplated and planned, the FDA recommends the serotonergic psychiatric medication be stopped at least 2 weeks in advance of methylene blue treatment and not resumed until 24 hours after the last dose of methylene blue. Specifically, fluoxetine, which has a longer half-life, should be stopped 5 weeks in advance.

The warning was updated in October 2011 as additional cases were brought to the attention of the FDA Adverse Event Reporting System. ${ }^{19}$ The FDA stated the cases of serotonin syndrome with methylene blue were with a selective serotonin reuptake inhibitor (SSRI), serotonin norepinephrine reuptake inhibitor, or clomipramine, a tricyclic antidepressant (Table 1). It is unknown whether the combination of methylene blue and other psychiatric medications has the same level of risk.

\section{CONCLUSIONS}

Depression is quite common in patients awaiting organ transplantation. Long-term illness, looming transplantation, the stress of an LVAD and its multiple potential complications, and the unpredictability of receiving a transplant even as a status $1 \mathrm{~A}$ all contribute to the psychiatric burden for these individuals. A review of post-LVAD patients by Shapiro and colleagues ${ }^{20}$ confirmed $83 \%$ required a psychiatric intervention and $20 \%$ had a major depressive episode. Although this is an older study at a single institution, it is representative of the LVAD population awaiting transplantation. At the University of Virginia, we reviewed the last 36 months and found 18 of 47 patients who underwent transplantation $(38 \%)$ were on an SSRI at the time of transplantation.

In an effort to balance the risks and benefits of antidepressant therapies, we have come to realize it is not possible to eliminate SSRIs from the management of depression in the LVAD patient population. Weighing the risks of serotonin syndrome, which only occurs in a small fraction of patients and is treatable with benzodiazepines and supportive care, vs the risk of untreated vasoplegia and potential endorgan damage and graft loss, we have continued to include methylene blue in the management of severe VS. As such, our current practice is to dose methylene blue 1 to 2 $\mathrm{mg} / \mathrm{kg}$ as a bolus over 20 to 30 minutes followed by 0.5 to $1 \mathrm{mg} / \mathrm{kg}$ per hour over 6 hours at the onset of refractory hypotension or at the time of delivery of the terminal warm cardioplegia dose immediately prior to unclamping and reperfusing the heart. For patients on an SSRI, it is our practice to exhaust more traditional inotropes, vasopressors, and volume resuscitation for the initial management of VS, and to reserve methylene blue for truly refractory hypotension.

Further research is needed to understand this issue more completely. The total number of patients on the transplantation list who are taking antidepressants is unknown at this time. We present this case as a means of generating discussion and to caution the use of methylene blue in transplant patients who are on antidepressant therapy.

\section{References}

1. Fischer GW, Levin MA. Vasoplegia during cardiac surgery: current concepts and management. Semin Thorac Cardiovasc Surg. 2010;22:140-4.

2. Gomes WJ, Carvalho AC, Palma JH, Goncalves I Jr, Buffolo E. Vasoplegic syndrome: a new dilemma. J Thorac Cardiovasc Surg. 1994;107:942-3.

3. Carrel T, Englberger L, Mohacsi P, Neidhart P, Schmidli J. Low systemic vascular resistance after cardiopulmonary bypass: incidence, etiology, and clinical importance. J Card Surg. 2000;15:347-53.

4. Patarroyo M, Simbaqueba C, Shrestha K, Starling RC, Smedira N, Tang WH, et al. Pre-operative risk factors and clinical outcomes associated with vasoplegia in recipients of orthotopic heart transplantation in the contemporary era. J Heart Lung Transplant. November 23, 2011 [Epub ahead of print].

5. Palmer RM. The discovery of nitric oxide in the vessel wall: a unifying concept in the pathogenesis of sepsis. Arch Surg. 1993;128:396-401.

6. Mayer B, Brunner F, Schmidt K. Novel actions of methylene blue. Eur Heart J. 1993;14:22-6

7. Argenziano M, Chen JM, Choudhri AF, Cullinane S, Garfein E, Weinberg AD, et al. Management of vasodilatory shock after cardiac surgery: identification of predisposing factors and use of a novel pressor agent. J Thorac Cardiovasc Surg. 1998;116:973-80.

8. Yiu P, Robin J, Pattison CW. Reversal of refractory hypotension with single-dose methylene blue after coronary artery bypass surgery. J Thorac Cardiovasc Surg. 1999;118:195-6.

9. Pagni S, Austin EH. Use of intravenous methylene blue for the treatment of refractory hypotension after cardiopulmonary bypass. J Thorac Cardiovasc Surg. 2000;119:1297-8. 
10. Andrade J, Batista M, Evora P, Tavares JR, Buffolo E, Ribeire EE, et al. Methylene blue administration in the treatment of the vasoplegic syndrome after cardiac surgery. Rev Bras Circ Cardiovasc. 1996;11:207-14.

11. Leyh RG, Kofidis T, Struber M, Fischer S, Knobloch K, Wachsmann B, et al. Methylene blue: the drug of choice for catecholamine-refractory vasoplegia after cardiopulmonary bypass? J Thorac Cardiovasc Surg. 2003;125:1426-31.

12. Levin RL, Degrange MA, Bruno GF, Del Mazo CD, Taborda DJ, Griotti JJ, et al. Methylene blue reduces mortality and morbidity in vasoplegic patients after cardiac surgery. Ann Thorac Surg. 2004;77:496-9.

13. Stanford SC, Stanford BJ, Gillman PK. Risk of severe serotonin toxicity following co-administration of methylene blue and serotonin reuptake inhibitors: an update on a case report of post-operative delirium. J Psychopharmacol. 2010;24:1433-8.

14. Gillman PK. CNS toxicity involving methylene blue: the exemplar for understanding and predicting drug interactions that precipitate serotonin toxicity. J Psychopharmacol. 2011;25:429-36.

15. Sternbach H. The serotonin syndrome. Am J Psychiatry. 1991;148:705-13.
16. Dunkley EJ, Isbister GK, Sibbritt D, Dawson AH, Whyte IM. The Hunter serotonin toxicity criteria: simple and accurate diagnostic decision rules for serotonin toxicity. Q J Med. 2003;96:635-42.

17. Boyer EW, Shannon M. The serotonin syndrome. N Engl J Med. 2005;352: 1112-20.

18. Food and Drug Administration. FDA drug safety communication: serious CNS reactions possible when methylene blue is given to patients takeing certain psychiatric medications. 2011. Available from: http://www.fda.gov/Drugs/DrugSafety/ ucm263190.htm. Accessed January 14, 2012.

19. Food and Drug Administration. FDA drug safety communication: updated information about the drug interaction between methylene blue (methylthioninium chloride) and serotonergic psychiatric medication. 2011. Available from: http:// www.fda.gov/Drugs/DrugSafety/ucm276119.htm. Accessed January 14, 2012.

20. Shapiro PA, Levin HR, Oz MC. Left ventricular assist devices: psychosocial burden and implications for heart transplant programs. Gen Hosp Psychiatry. 1996; 18:30S-5S.

\title{
The reliability of lung function tests in a quadriplegic patient
}

\author{
Pierre Emmanuel Noly, MD, Alex Arame, MD, Marc Riquet, $\mathrm{PhD}$, MD, and \\ Françoise Le Pimpec-Barthes, PhD, MD, Paris, France
}

There are few quadriplegic patients who require thoracic surgery. ${ }^{1}$ A weak capability to cough may lead to retention of pulmonary secretions and consequently life-threatening infectious complications, ${ }^{2}$ particularly during the postoperative course. Surgery remains the only radical treatment of endangering conditions, such as lung aspergilloma complicated by hemoptysis. ${ }^{3}$ Lung resection usually requires a predicted postoperative forced expiratory volume in 1 second $\left(\mathrm{FEV}_{1}\right)$ exceeding $30 \%$; otherwise, resection may be associated with a high postoperative mortality.

\section{CLINICAL SUMMARY}

A 35-year-old man was involved in a motor accident (12 years previously) causing T8 paraplegia complicated by phlebitis and pulmonary embolism. He underwent T3-L3 arthrodesis 7 years later to correct post-traumatic kyphoscoliosis that was complicated by C6 quadriplegia (with partial left arm mobility) and several bacterial pneumonias resulting in destruction of the right upper lobe, followed by aspergilloma formation and mild hemoptysis occurring several times per day. Treatment with an oral

From the Department of Thoracic Surgery, Georges Pompidou European Hospital, Paris-Descartes University, Paris, France.

Disclosures: Authors have nothing to disclose with regard to commercial support.

Received for publication March 22, 2012; revisions received July 5, 2012; accepted for publication Aug 1, 2012; available ahead of print Aug 23, 2012.

Address for reprints: Marc Riquet, PhD, MD, Department of Thoracic Surgery, Georges Pompidou European Hospital, 20 rue Leblanc 75015, Paris, France (E-mail: marc.riquet@egp.aphp.fr).

J Thorac Cardiovasc Surg 2012;144:e116-7

$0022-5223 / \$ 36.00$

Copyright (c) 2012 by The American Association for Thoracic Surgery

http://dx.doi.org/10.1016/j.jtcvs.2012.08.001 antifungic drug was stopped because of liver complication (cytolysis). Itraconazole proved to be ineffective. Aspergillous serology remained positive, and hemoptysis continued. Lobectomy was declined by 2 thoracic surgery centers because of the patient's low $\mathrm{FEV}_{1}: 570 \mathrm{~mL}$ (13\% of the predicted value).

The patient was referred to the Georges Pompidou European Hospital. He had no dyspnea, and room air saturation was $99 \%$ at rest. He was able to move himself using a wheelchair, but he had swallowing problems and an inability to cough. No abdominal muscle activity or accessory respiratory muscle contraction was observed. After 2 weeks in a pulmonary prehabilitation program, spirometry did not improve. $\mathrm{FEV}_{1}$ was still $13 \%$, vital capacity was $25 \%$ $(1350 \mathrm{~mL})$, and diffusing capacity of the lung for carbon monoxide was $37 \%$. Arterial oxygen tension was $100 \mathrm{~mm}$ $\mathrm{Hg}$, and arterial carbon dioxide tension was $45 \mathrm{~mm} \mathrm{Hg}$. However, except for an aspergilloma, the lung parenchyma was disease-free on the computed tomography scan, and lung perfusion was uniformly homogeneous in both lungs on ventilation-perfusion scan. We suspected that the real respiratory function was underestimated by spirometry and not interpretable in this patient. C6 quadriplegia explained the respiratory weakness with an $\mathrm{FEV}_{1}$ less than $20 \%$ of predicted. A right upper lobectomy was performed by video-assisted thoracoscopic surgery. A temporary prophylactic tracheostomy was performed to manage postoperative expectorating incapability problems and swallowing difficulties. The postoperative course was uneventful. The patient was weaned from mechanical ventilation within 24 hours, and the tracheostomy tube was removed on postoperative day 9. Intense chest physiotherapy continued 